\title{
Postnatal Care Practices among the Malays, Chinese and Indians: A Comparison
}

\author{
Zuraidah Mohd Yusoff ${ }^{1}$, Asmiaty Amat ${ }^{2}$, Darlina Naim $^{1}$ and Saad Othman ${ }^{1}$ \\ ${ }^{1}$ Universiti Sains Malaysia, Penang, Malaysia \\ ${ }^{2}$ Universiti Malaysia Sabah, Kota Kinabalu, Sabah, Malaysia
}

\begin{abstract}
In Malaysia, each race has its own traditional medicine practice which has existed for hundreds of years before the coming of modern medicine. Also, each race has many kinds of practices that had been around maintaining the health care of the respective community. All of these races or ethnic groups regard that it is very important for new mothers to be nursed back to health and thus each has its own specific and special postnatal or maternity care. The treatment during the postnatal or confinement period is generally considered to be good and safe and can help the new mother to gain back her health to the pre-pregnancy status. It is also belief that the ingredients used are natural and usually do not caused harm to the mother's condition. Hence, this paper is the result of the study on the traditional postnatal care practiced by the Malay, Chinese and Indian communities in Malaysia. This study was conducted through interviews and review of literature. The results obtained showed that there are a variety of treatments and practices during postnatal or confinement period for each of the race. In addition, traditional postnatal care during confinement are still being sought after and followed by the different races in Malaysia.
\end{abstract}

\section{Introduction}

According to the World Intellectual Property Organization (WIPO), traditional knowledge is a living body of knowledge, skills and practices developed by the indigenous or local communities and are sustained as well as inherited from generation to generation within a community. This often become part of its cultural and spiritual identity. One of this knowledge is in the practice of traditional medicine. World Health Organization (WHO) defines traditional medicine as health practices, approaches, knowledge and beliefs incorporating plant, animal and mineral based medicines, spiritual therapies, manual techniques and exercises, applied singularly or in combination, to treat, diagnose and prevent illnesses or maintain well-being. Hence traditional medicine based on traditional knowledge is a medical practice that has long existed in the community prior to the introduction and influence of modern medicine. Currently, traditional medicine is growing worldwide and has become one of the most important branch of medical science giving many impacts towards improving the health of the community. Traditional medicine of course also reflects the background and the origin of a culture. In other words, even though modern medicine has reached the era of globalization, traditional medical practices are not being side-lined or neglected but in fact are still being in demand.

Malaysia is a country with multiracial population with Malay, Chinese and Indian constituting the majority of the population. Each of these races is rich in traditional knowledge and practices that has been in place for centuries. Thus the diversity of races in Malaysia has further enhanced the practice and health care of the country.

One important area of the traditional medicine is involved with the birthing practice observed by women. The traditional birthing practice is defined as all beliefs, behaviours and rituals done during the ante-natal, labour and birth and the post-natal period. These practices are socially constructed and shaped by the perception and practice of the culture. Hence many cultures or ethnicities around the world practice specific postnatal rituals or treatment. This is said to avoid ill health in later years even though at times the immediate effects are not felt. These postnatal practices or rituals would permit the mother to be pampered for a period of time after giving birth. Some of the rituals includes 
defined period of rest, hygiene practices, food restriction and recommended, special treatment for the mothers as well as breastfeeding and infant care. However with modernization and globalization these post-natal rituals might not be practiced or followed. In Malaysia, the Malays, Chinese and Indian communities do have their own belief and practice in the postnatal care. Thus this paper will focus and describe the postpartum practices in these three major ethnic groups and to identify the similarities and differences in this traditional postnatal belief and practice.

\section{Maternity Confinement}

Maternity Confinement is one of the traditional treatment which has become a tradition for women who have given birth to a baby. The purpose of confinement is to heal and restore energy and health within a specified period of time. Each race has its own unique methods of post-natal care be it the Malays, Chinese or Indians. Although the Chinese in Sabah and in Peninsular Malaysia are of the same ethnicity however the practice during confinement is a little different because the culture and practice of the Chinese community in Sabah has assimilated with the indigenous communities of Sabah.

\section{Midwifery Practice Among Malay, Chinese And Indian}

The Malay midwife is called a 'bidan' who traditionally play an important role in the Malay women health. In obtaining more information on traditional Malay medicine and postnatal care specifically, interview was conducted with a Malay traditional medicine practitioner who is still actively practicing traditional Malay midwifery. The 'bidan' is 62 years old, from Teluk Kumbar, Penang and has been in the field of midwifery for about 27 years. According to her, the midwifery skills she acquired are inherited through generations from her mother side. While the information regarding the confinement practice among the Chinese was obtained from the interviews with two Chinese women who have just given birth together with the midwife who took care of them during labour. This Chinese midwife is called 'Yuet Pui Pok' or "Pui Yit" or confinement nanny which literally means companion grandmother. The information relating to postnatal practices among the Indian was obtained from an interview with an Indian lady from Penang.

According to the Malay midwife, care of women after childbirth is very important for maintaining the health of the women so she would recover and be back to the normal status as well as to maintain the health of the reproductive system of women after childbirth. Midwifery or postnatal care can only be started one or two weeks after the childbirth. This ensures the stitches during childbirth or labour have healed to avoid any other complications that may occur.

For the Chinese, they will recruit and hire a trained confinement lady (companion grandmother) to take care of them during the process of confinement The confinement lady is paid not only to take care of the new mother but will also take care of the new born for a certain time period. The confinement lady will take care of the new mother's bathing needs as well as her diet for 30 days. Hence for this, the confinement lady will be paid with a modest salary. Nowadays maternal care institutions have been commercialized and extremely well received in the Chinese community. Although it looks quite modern and with efficient management, postnatal or maternity care practices still follow traditional features.

The traditional Indian postnatal practices is to help the mother to revitalise her body by making it warm again. The belief is that blood lost during labour had caused the body to go into a cold stage. The confinement period is for 30 days whereby many special practices are being followed. For those families who could afford, a special assistant or maid would be employed that looks after the mother and the baby. Otherwise, an elderly member of the family would come to help.

\section{The Malay Postnatal Care Or Confinement.}

According to the WHO, the postpartum period starts about 1 hour after the birth of the placenta when immediate care of the mother and the infant starts. Although not officially sanctioned, traditionally the postpartum period is supposed 
to end 6 weeks after birth. The period of 6 weeks fits very well into cultural traditions in many countries, where often the first 40 days after birth are considered a time of convalescence for the mother and her new born infant. The postnatal or post-partum or confinement period observed by the Malay women is usually 44 days although a longer period of 60 days or 100 days are followed by some. Special precautions are followed for those women who had undergone Cesarean (surgery) birth as compared to those with normal birth.

Among the Malay community, the usual postnatal treatment or midwifery care involved during the confinement period nowadays are hot compress (bertungku), heat treatment (berdiang), herbal bath, body wrap (berbengkung/berbarut), and body massage. Also during this confinement period, food that are considered as cold, 'windy' and poisonous are prohibited. Examples of prohibited food are cucumber, long beans, bamboo shoots, pineapples, crabs, and certain types of fishes. Hence food which are categorized as hot are consumed. The women are also encourage to consumed tonic drink (jamu) or herbal paste (makjun) made from herbs which is considered as hot.

\subsection{Hot Compress (Bertungku)}

Hot compress is a form of point massage using heated objects. There are two types of 'tungku' (apparatus used for hot compress) that could be use i.e. iron 'tungku' (club-like iron with a handle) or stone 'tungku' (sphere-shaped river stone). These 'tungku' are of varying weights and the weight used would depend on the size of the woman's body and usually the two kilogram 'tungku' is being used. If a woman is an obese, a heavier 'tungku' tends to be more suitable for optimum impact. To prepare the hot compress, the 'tungku' is heated up and then placed on some herbal leaves such as Alpinia galangal (lengkuas) and Morinda Citrifolia (mengkudu) before being wrapped in a cloth. Then using specific technics the hot compress is being applied to areas of the body such as the abdomen and thigh applied. Traditionally, the hot compress is applied for at least half an hour to an hour

\subsection{Heat Treatment (Berdiang)}

The treatment is performed using a brick wrapped with a variety of herbs such as piper sarmentosum (kaduk) leaves, Erythrina fusca Lour leaves (dedap), Piper betle leaf (sirih), lemongrass and ginger. The bricks are heated before being wrapped with the leaves and a piece of cloth. It is then placed beside the body of a woman i.e. approximately two inches from the body. This process can be done while the woman is lying down or when she is asleep. According to the Malay midwife, the process is very effective in removing toxic substances from the woman's body through her sweat.

\subsection{Herbal Bath}

For some of the Malays, there are practices that do not allow mother after childbirth to bath for the next three days. However after the childbirth, the mother's body would be wipe with warm water for blood to flow better. However, this is not observed by some whereby they are allow to bathe a day after delivery. Woman in the confinement period is also advised not to bathe in the early morning as to avoid the 'wind' from entering the body and causing body aches and pains. During the herbal bath, the temperature of the water need to be warm to hot (preferably hot) and with various types of herbs such as Desmodium gangeticum (daun Meringan) added. At the same time, simple massage in the water is performed on the woman's body so as to soften all the taut and strained muscles during the process of giving birth.

\subsection{Whole Body Massage}

The type of massage after childbirth is the deep tissue and therapeutic whole body massage and is performed by the Malay midwife who is an experienced masseur. The part of the body to initiate the massage would depend on the midwife. As for the midwife interviewed, the massage technique would starts from the top of the head and ends at the feet. Massage therapy is fundamental to accelerate blood flow because it is believed that after giving birth, the blood flow in the woman's body slows down and will cause her to experience body pain and numbness. Correct and suitable massage technique is very important so as to get the best effect. The most important part of the body is in the nerves 
and muscle of the thigh, hip and the back. Usually the mother could opt for various number of massage sessions however a minimum session recommended is three.

\subsection{Body Wrap (Berbengkung/Berbarut)}

Barut or body wrap or abdominal binding is another common treatment performed during postnatal care. This is done by smearing or spreading an herbal paste made from specific herbs and spices on the entire abdomen before binding was done. Tight wrapping or binding is done by using a piece of long cloth (corset like) covering the abdomen area starting from just beneath the breast to the thighs. The size of the barut would depend on the woman's body size. This treatment aims to restore and deflate the woman's abdomen after child-birth and to regain the mother' original body posture and shape.

\subsection{Vagina Steaming (Tangas)}

Vagina steaming or tangas in Malay is a traditional method that uses steam derived from herbal mixture. This tangas treatment is given with the woman sitting on a wooden chair that has an opening in the middle of the perineum area thus exposing to the steam or vapour coming from a bucket of steaming water with herbs in it. This tangas treatment is intended to lift up the uterus back to its original position and also to shrink the uterus which has expanded during pregnancy. Tangas would also make the body feels lighter and comfortable. This is usually performed in the final phase of the 44 days confinement.

\section{The Chinese Postnatal Care Or Confinement}

For the Chinese community, the confinement period observed by woman who had given birth depends on the individual but usually it spans a period of one month (30 days) or up to 44 days as the duration observed by the Malay woman. For the Chinese women who really adhere to the practice of confinement, they are not allowed out of the house for the entire confinement period.

The basic principal the Chinese woman most adhere to during this confinement time is keeping the body away from colds (wind). As a result, the woman in confinement would not bathe for several days or weeks (depending on her endurance, namely comfort). It is also believed that bathing would cause evil 'wind' entering the body and causing joint pain. After several weeks, the mother will be bathe with water that has been boiled and let cooled down (relatively warm temperatures). The hot water need to cool down on its own and cold water is not allowed to be mixed with hot water so as to cool it. The bath water is then usually mixed with the leaves or roots of bitter melon or bitter gourd (Momordica charantia). Herbs for the bath is also easily available and sold in the shops of traditional Chinese medicine. Chinese woman in confinement is strictly not allowed to wash her head for fear she will be hurt as a result of the cold. In Sabah, the Chinese and Indigenous woman specifically use water mixed with the herb 'sambungsambung' (Blumea balsamifera) the confinement bath. This herb is said to be good in preventing the body of the woman in confinement from wind (cold) and thus avert from body aches. There is also a practice of the Chinese community not allowing the use of fan for 30 days. However, this matter is seldom practiced by modern society.

In addition to bathing care, the Chinese are also very concerned with food and nutrition during the confinement period. During this period the woman is not encouraged to drink lot of plain water instead the decoction of dried longan and red dates are preferred. The Chinese society also emphasized on taking herbs such as ginseng soup, red date and 'lihing' during confinement. According to the midwife, the Chinese community in the state of Sabah practice drinking 'lihing', which is a type of liquor made from fermented rice and cooked with chicken and ginger. This soup is consumed so as to get rid of the 'wind' in the body and to warm-up the body of mother who had given birth. As for the Chinese community in peninsula Malaysia, the food for woman during confinement are specific fishes that are considered not harmful and do not cause itching such as pomfret, red fish and white fish cooked with sesame oil and ginger. While the vegetables are very important in the diet, Chinese society does not encourage the consumption of vegetables during confinement since most of the vegetables are considered cold and cause the body to become weak and caused joint pains. For the Chinese postnatal care, body wrap (berbarut) and hot compress (bertungku) are not usually performed. 
In addition, emphasis is also given to the new-born. As an example, in Sabah eucalyptus oil is applied to the whole body of the baby before and after bathing. According to the practice of Chinese community, the baby will be bathed with a mixture of herbs such as the roots and leaves of bitter melon (Momordica charantia) because it is believed to prevent the baby from jaundice and trapped wind.

\section{The Indian Postnatal Care Or Confinement}

The postnatal practices among the Indians are rather similar to those practices among the Malays. After delivery the woman or new mother is allowed to bathe but only with warm water that has been boiled with herbs such as neem (Azadirachta indica), mengkudu (Morinda citrifolia) and lemuni Vitex Trifolia var Negundo) leaves. However, washing the hair daily is not allowed in order to prevent cold. Hair washing is done on odd number days such as day $3,5,7$ until the 1 month confinement is over. The hair need to be dried quickly since it is belief that leaving it wet can cause post-partum depression. The woman is not allowed to bath too early in the morning but can only do so after sunrise or mid-morning. She is also required to keep her body warm at all time. During bathing, body scrub (lulur) made from herbs including turmeric is applied.

Similar to the Malay and the Chinese, the Indian also observed some food restriction during the confinement period. Food that are considered 'cold' or 'windy' should be avoided. Examples of these food are cucumber, murungai (Moringa oleifera) fruits, eggplant, jack fruit and grapes. However, some food are encourage such as shark meat and boiled fenugreek seeds are said to increase milk production. Spices such as black pepper, cardamom, aniseed, turmeric, ginger are also encouraged to be added to the food. The woman is given herbal concoction (makjun) to be consumed during the confinement period. The woman is allowed to drink warm water in moderation but ice cold water is prohibited.

Just like the Malays, the Indian postnatal care or practice also apply massage or maalish to the new mother. This is done daily by using oil such as neem oil, mustard oil or coconut oil. Among the Indian, postnatal girdle (bengkung) is also used. This is done by applying the oil on the mother's abdomen and binds it tightly with a long cloth so as to tighten up the flaccid muscle. Hot compression is not done in postnatal care among the Indian.

Right after delivery, the new-born will be whispered with the name of the Hindu god. At 16 days old, special prayer is done for the new-born at home and at 30 days the new-born will be taken to the temple for prayer to be recited for $\mathrm{him} / \mathrm{her}$. Usually food would be served to family members and friends attending the occasion. The new-born also undergoes daily massage with oil being applied to the entire body. It is thought to be good for the baby's bone and overall development.

\section{Conclusion}

There are similarities and differences in the practice of postnatal care among the Malay, Chinese and Indians. The similarities are the practices in ensuring recovery and restoring the health of women after childbirth back to nonpregnant status in a defined confinement period. The basic factor in the postnatal care that was greatly emphasized by the three races is the fear of the 'wind' and cold which can caused illnesses such as body aches, fever and bloating in the woman which would hinder recovery. Food restriction is being observed in all the three races. The slight differences observed in the concept and practice between the three races is due to the different culture inherited from the elderly. 


\section{References}

1. Anisah Barakbah (2007). Ensiklopedia Perbidanan Melayu. Sebuah Perbendaharaan Ilmu

2. Perubatan dan Penjagaan Kesihatan. Utusan Publication \& Distribution Sdn. Bhd.

3. Azuzay Zamani (2001). Traditional Practices In Postnatal Care: The Malay Community In Malaysia. Trinity Student Medical Journal . 2. Pp 30-31

4. Cindy-Lee Dennis, Kenneth Fung, Sophie Grigoriadis, Gail Erlick Robinson, Sarah Romans \& Lori Ross (2007). Traditional Postpartum Practices And Rituals: A Qualitative Systematic Review. Women's Health . 3(4), pp487-502

5. Eliana Nasir, Sandra Mackey, David Arthur, Piyanee Klainin-Yobas, Helen Chen and Debra K. Creedy (2012). An Exploratory Study Of Traditional Birthing Practices Of Chinese Malay And Indian Women In Singapore. Midwifery 28,e865-e871

6. Indian confinement practices https://www.babycenter.com.my/a1042118/indian-confinement-practice.

7. Lenore Manderso. (1981) Roasting, Smoking And Dieting In Response To Birth: Malay Confinement In Cross-Cultural Perspective . Soc, Sci \& Med 15B, pp 509-520

8. MHishamshah, Mbin Ramzan, A Rashid, W Wan Mustaffa, R Haroon, N Badaruddin (2010). Belief and Practices of Traditional Post Partum Care Among a Rural Community in Penang Malaysia. The Internet Journal of Third World Medicine. 9 (2), pp1-9

9. Poh Bee Koon, Wong Yuen Peng \& Norimah A. Karim (2005). Postpartum Dietary Intakes and Food Taboos Among Chinese Women Attending Maternal and Child Health Clinics and Maternity Hospital, Kuala Lumpur Mal J Nutr 11(1), pp1-21

10. Samad. A. (2005). Warisan Perubatan Melayu. 2nd Edition. Dewan Bahasa \& Pustaka, Kuala Lumpur.

11. Siti Zubaidah, Norsuhana Ah dan Fatan Hamamah (2012). Penggunaan Haiwan bagi Perubatan Tradisional dalam Kalangan Masyarakat Pribumi di Asia: Satu Ulasan. Pahang: Universiti Sains Malaysia.Unschuld P.U. 1985. Medicine In China: a history of ideas. United States of America : University of California

12. WHO, Geneva (1998). Safe Motherhood. Postpartum Care of the Mother and Newborn: A Practical Guide

13. WHO (2003). Traditional Medicine. WHO, Geneva. SSN 1393-9572. Kuala Lumpur

14. World Intellectual Property Rights (WIPO 2015). Traditional knowledge and intellectual property background brief. Retrieved from http://www.wipo.int/pressroom/en/briefs/tk_ip.html.

15. Wong KC \& Wu L-T. 1932. History of Chinese Medicine. China: The Tientsin Press 